\title{
Self-reported mental health in 12-year-old second-generation immigrant children in Sweden
}

\author{
Linda Dekeyser, Carl Göran Svedin, Sara Agnaförs and Gunilla Sydsjö
}

\section{Linköping University Post Print}

N.B.: When citing this work, cite the original article.

Original Publication:

Linda Dekeyser, Carl Göran Svedin, Sara Agnaförs and Gunilla Sydsjö, Self-reported mental health in 12-year-old second-generation immigrant children in Sweden, 2011, Nordic Journal of Psychiatry, (65), 6, 389-395.

http://dx.doi.org/10.3109/08039488.2011.566936

Copyright: Informa Healthcare http://informahealthcare.com/

Postprint available at: Linköping University Electronic Press

http://urn.kb.se/resolve?urn=urn:nbn:se:liu:diva-72248 


\title{
Self-reported mental health in 12-year old second-generation immigrant children in Sweden
}

\author{
Linda deKeyser ${ }^{1,2}$ Carl Göran Svedin ${ }^{1}$, Sara Agnafors ${ }^{1}$ Gunilla Sydsjö ${ }^{2}$
}

\author{
${ }^{1}$ Division of Child and Adolescent Psychiatry and ${ }^{2}$ Division of Obstetrics and \\ Gynaecology , Department of Clinical and Experimental Medicine, Faculty of Health \\ Sciences, Linköping University, SE-581 85 Linköping, Sweden
}

\section{Correspondence:}

Sydsjö Gunilla, Division of Obstetrics and Gynaecology, IKE, Faculty of Health Sciences, Linköping University, S-581 85 Linköping. Sweden

Tel: +46-10-1033167

Fax: +46-13-145186

Email: Gunilla.Sydsjo@lio.se 


\begin{abstract}
Background: Today $29.3 \%$ of all newborns in Sweden are second generation immigrants. Studies on mental health among these children are few, inconclusive and vary widely with regard to the informant used and the age of the immigrant. The majority of previous studies focus on study groups that cover a wide age span but since mental health varies considerably during the preadolescent and adolescent years more agespecific studies are needed. Additional focus on the health and well-being of these children is necessary if a well-functioning society is to develop.
\end{abstract}

Aim: To investigate if and how second-generation immigrant children in Sweden differ from non-immigrant children in their presentation of self-reported mental health at the age of 12 .

Methods: Second-generation immigrant children $(n=142)$ from a birth cohort in southern Sweden, subjects of the SESBiC-study (the South East Sweden Birth Cohort-study) were compared to non-immigrant children $(n=1036)$ from the same cohort in their presentation of self-reported mental health at the age of 12 using the Strengths and Difficulties Questionnaire. Gender, family structure and parents`educational level were controlled for.

Results: Second-generation immigrant children did not differ from the non-immigrant children in their own presentation of mental health at the age of 12 in any of the categories of immigrant groups.

Conclusion: It is a promising sign for future integration that second-generation immigrant children's self-reported mental health at the age of 12 that was quite similar to that of non-immigrant children.

\title{
Keywords
}


Children, mental health, second-generation immigrants, SESBiC-study, Strengths and Difficulties Questionnaire 


\section{BACKGROUND}

In contrast to the ethnically homogeneous society Sweden used to be, people from all over the world have immigrated to Sweden over the past several decades. Today $29.3 \%$ of all newborns in Sweden (1) and 14\% of adolescents in junior high school (2) are second generation immigrants, children born in Sweden with at least one parent born in a foreign country. This major change in composition of the population over a short period of time calls for additional focus on the health and well-being of these children if a wellfunctioning society is to develop.

Second-generation immigrant children might be at increased risk for mental health problems for reasons such as intergenerational conflicts due to asymmetric acculturation within the family, lack of adequate support from their parents due to their parents' preoccupation with their own migration stressors and restrictive processes due to discrimination and a weak social position in the society. Cultural characteristics that differ from previous Swedish norms, characteristics such as family roles, values and religiosity could contribute to a better or worse mental health depending on the person involved. The impact of migration on mental health varies within different migrant groups and host countries as well as different reasons for migrating (3-5).

In a recent review of mental health among migrant children, the results were inconclusive (3). There was no unequivocally increased risk of mental health problems in migrant children, but since the studies in the field varied widely with regard to characteristics of the immigrant group, country of origin, host country, definition of immigrants (first- and/or second generation), informant (self-, parent- or teacher-reports), age and gender of the immigrant, it was difficult to draw any sound conclusions.

The following studies referred to are self-reported studies of second-generation immigrant adolescents (or both first- and second generation immigrants where it was 
made clear that a clear majority were immigrants of the second-generation) only. Compared to native adolescents, similar behaviour problems were reported by immigrants in Australia $(6,7)$ and Pakistani immigrants in Norway (8) as well as similar internalising $(9,10)$ and externalising problems $(9,11,12)$ by immigrants in the Netherlands. Turkish immigrants in Sweden (8) and Vietnamese refugee immigrants in Norway (13) reported fewer behaviour problems and immigrants in the Netherlands reported fewer externalising problems (10) compared to the native adolescents. More internalising problems were reported among immigrants in the Netherlands $(11,12)$ compared to the native Dutch adolescents.

There are few studies that compare mental health among first- and secondgeneration immigrants in Europe, however most studies in the United States and Canada report an increased risk of behaviour problems, drug use and harmful drinking among second-generation immigrants compared to first-generation immigrants (14-17). Pumariega and co-workers suggest that it may be a result of that second-generation immigrants face different stressors than the first-generation immigrants, for example the stress of social adversity and discrimination without having a secure identity or traditional values of their parents. Among first generation immigrants depression and anxiety is overrepresented, perhaps due to stressors like poverty, unemployment and low self-esteem (16)

The majority of the studies focus on their respective study groups covering a wide age span, sometimes more than 8 years. Only the Dutch study of 11-year old immigrant children (9) and the Australian study of 14-year old immigrant children (6) studied a specific age group. Since mental health in general varies considerably during the preadolescent and adolescent years (18) more age-specific studies are needed. 


\section{AIM}

The aim of the present study was to investigate if and how second-generation immigrant children in Sweden differ from non-immigrant children in their presentation of selfreported mental health at the age of 12 with gender, parental immigrant status and country of origin all being taken into consideration.

\section{MATERIAL AND METHODS}

\section{Subjects}

This cross-sectional study is a part of a longitudinal birth cohort study from the south east of Sweden (the South East Sweden Birth Cohort-study, the SESBiC-study) on children's mental health. All children born in the catchment areas of Hässleholm and Western Blekinge in the south of Sweden between May 1st 1995 and December 31st 1996 were invited to take part. The mothers of 1723 children (88\%) accepted of which $236(14 \%)$ were second-generation immigrants. Two follow-ups of the cohort have been performed in connection with routine examination at age 3 and 5.5 at the child welfare centres. At the first follow-up, 1439 of the original 1723 agreed to participate (84\%) and at the second follow-up at the age 5.5, due to different child welfare centre protocols, only the sample from Hässleholm area participated. The results from the follow-ups at 3 years of age and 5.5 years of age have been reported by Cederblad et al. (19-22). At the 12 year follow-up 2 had died, 11 had moved from the country and 24 were learning-disabled and could therefore not participate and were excluded from the original 1723 in the baseline study which leaves 1686 subjects. Parents of 1178 children (70\% of the 1686 subjects) agreed to participate. Of those, 142 children (12\%) were second generation immigrants. 


\section{Procedures at the 12 year follow-up}

Current home addresses and information about the school and class each child was attending were obtained from the Swedish Tax Office and from local education offices respectively for the children. After principals were informed about the study's aim and design they all agreed to participation. Parents (i.e. legal guardians) received written information about the study as well as a consent form to sign in order to allow the child to participate in the study. Parents were reminded by phone if the consent form was not returned. The children received a simplified information letter.

Research assistants met with the children of parents who had given their consent to participate in groups of 5-20 in school during school hours. All questions were read out loud by the research assistant and the children filled out the questionnaires without talking to each other. Children who no longer lived in the area or were not in school that day were scheduled for a home visit or a meeting at their new school. The individual child was given the same oral information and the research assistant was present in the room during the entire time when the questionnaire was being filled out by the child. In a few cases on the participant's or parent's initiative the questionnaires were sent by mail to their home address.

The mother and father separately, were asked to fill out and return a different study questionnaire that was sent to their home address.

\section{Immigrant variables}

All children whose parents were both born in Sweden were considered non-immigrants. All children who had at least one immigrant parent were considered to be second-generation immigrants. The children were further divided into different categories of groups. In the first category the children were placed into four groups based on both parent's immigrant status. The first group, the non-immigrant group, consisted of children whose parents were both born 
in Sweden $(n=1036)$. The second group consisted of children whose mother was an immigrant and the father was born in Sweden $(n=40)$. The third group consisted of children whose father was an immigrant and the mother was born in Sweden $(n=35)$. The fourth group consisted of children whose parents were both immigrants $(n=67)$.

In the second category, the children were placed into four groups based on the parent's country of origin. The first group, the non-immigrant group, consisted of children whose parents were both born in Sweden $(n=1036)$. The second group consisted of children whose parents (at least one) were born in a Nordic country (excluding Sweden, n=29). The third group consisted of children whose parents (at least one) were born in a European country (excluding the Nordic countries, $n=62$ ). The fourth group consisted of children whose parents (at least one) were born outside of Europe $(\mathrm{n}=51)$. If a child's parents belonged to two different groups, the child was placed in the group that is geographically furthest away from Sweden of the two.

\section{Child variables}

To assess the children's mental health the Strengths and Difficulties Questionnaire - the self report version (SDQ-s) was used. SDQ is a screening instrument, used in many industrialized and less developed countries worldwide, designed to measures both positive and negative behavioural attributes in children and adolescents, was used $(23,24)$. The questionnaire consists of 25 items divided between four problem subscales (emotional-, conduct-, hyperactivity- and peer problems) and one strengths subscale (prosocial behaviour). The sum of the four problem subscales generates a total difficulty score (23). It has shown good reliability and validity as a screening tool in different populations (25) used originally for children aged 4-16 years (26) and, recently, also for 17-19 year olds (27). In this study 
Cronbach's alpha for the total scale was 0.66 ( 0.67 for non-immigrants and 0.55 for secondgeneration immigrants).

Information concerning parents' country of origin, maternal life stress score (accumulation of social-, medical- and psychological stress factors) and the level of acculturation in the family i.e. if one or two parents were immigrants, if mother had lived at least five years in Sweden when the child was born, if Swedish at least partly was spoken at home, if country of origin was a Nordic or European country vs. a country outside of Europe was gathered at the time of the baseline study, i.e. when the children were 3 months old. Information about family structure, i.e. if the children's parents were living together or not, was collected from the children's questionnaires at the 12 year follow up. Information about the parent's educational level was collected from the parent's questionnaires at the 12 year follow up. The children were considered to be in the university/college degree group if at least one of their parents had higher education. If not, they were considered to be in the compulsory secondary schooling/high school group.

\section{Drop out rate and analysis}

The total drop out rate was $30 \%$. As participants and non-participants were compared regarding parental immigrant status, parental country of origin as well as maternal life stress score, statistical difference were found. Children of two immigrant parents had a drop out rate of $46 \%$ compared to $33 \%$ among children of immigrant fathers, $29 \%$ among children of immigrant mothers and $28 \%$ among non-immigrant children $(P<0.001)$. Children whose parents came from a country outside of Europe had a drop out rate of $40 \%$ compared to $35 \%$ for children of parents from a European country, $29 \%$ among the children of parents from a Nordic country and $28 \%$ for non-immigrant children $(P=0.05)$. Children whose mothers had a high life stress score had a higher drop out rate, $40 \%$ compared to $29 \%$ among children whose 
mothers did not have a high life stress score $(P=0.01)$. However, there were no significant difference in maternal life stress score or family acculturation level among participant and non-participant children of two immigrant parents or children whose parents came from a country outside of Europe. Further, there was no significant difference between participants and non-participant at the 12-year follow up regarding earlier emotional and behaviour problems documented in the SESBiC-study at the age of 3 (19).

\section{Ethical considerations}

The study was approved by the Ethics committee of the University of Lund and the Ethics committee of the University of Linköping.

\section{Statistics}

When data were considered as dichotomous, as in a previous study of a Norwegian representative sample (28), the $90^{\text {th }}$ percentile was used as a cut off to indicate high scores on the SDQ problem subscales and the total scale.

The $10^{\text {th }}$ percentile was used as a cut off to indicate low scores on the strength subscale. The cut offs for the problem- and total scales were: emotions (0-5 low, 6-10 high), conduct (0-3 low, 4-10 high), hyperactivity (0-6 low, 7-10 high), peer problems (0-4 low, 5-10 high), total score (0-19 low, 20-40 high) and for the strengths scale: prosocial (0-5 low, 6-10 high). To check potential differences between the chosen dichotomous model and analysing the whole variation of the SDQ scales t-test was used.

All analyses were performed using the SPSS program, version 17.0 (SPSS Inc., Chicago, IL). Statistical significance was defined as (two-sided) $P \leq 0.05$. In order to assess differences on SDQ problem and strength subscales, as well as total scale with respect to gender, immigrant status and immigrant background, Chi-square test or 
Fisher's Exact test was used, in both cases two sided. To further assess differences with respect to immigrant status, logistic regression was performed with SDQ scores as dependent variables (indicator for low/high). The independent variables were immigrant status, gender of child, family structure and parental education where the variable addressed 0 were used as the reference level. For the drop out analysis Chi-square test was used.

\section{RESULTS}

The second-generation immigrant children as a group did not differ significantly from the non-immigrant children in their self-reported mental health, table 1, and the same was true when stratified for parental immigrant status (the first category group), parents' country of origin (the second category group) and when second-generation immigrant boys and girls were analysed separately.

In multivariate analysis, gender was an independent predicting variable for the subscales Emotional-, Conduct-, Hyperactivity problems as well as Prosocial strengths, after adjusting for the variables immigrant status, family structure and parental education, table 1 . Girls had almost three times the frequency of Emotional problems $(P<0.001)$ that boys had. Boys on the other hand had more than double the frequency of Conduct problems $(P<0.001)$, Hyperactivity problems $(P=0.001)$ as well as a three times increased risk of deficiencies in Prosocial behaviour compared with girls $(P<0.001)$ compared with girls.

In the multivariate analysis, family structure was also an independent predicting variable for the subscale Peer problems, after adjustment for the variables immigrant status, gender and parental education, table 1 . The children who were not living with both parents had more than double the frequency of Peer problems $(P=0.008)$ seen in the children who were living with both parents. 
In the multivariate analysis, parental education was also an independent predicting variable for the subscales Hyperactivity problems and Total difficulty score after adjustment for the variables immigrant status, gender and family structure. Children whose parents had low educational level had more Total problems $(\mathrm{P}=0.05)$ and double the frequency of Hyperactivity problems $(P=0.012)$ seen in children whose parents had high educational level.

Of the children whose parents were both immigrants, the majority of the parents came from a European country. Of the children whose fathers were immigrants and the mothers non-immigrants, the majority of the fathers came from a Nordic country. Of the children whose mothers were immigrants and fathers non-immigrants, the majority of the mothers came from a European country or from a country outside of Europe. There were no significant differences in the children's mental health (SDQ total score and subscales) neither when categorizing for immigrant status or country of origin. There were no significant differences in family structure, i.e. whether the parents were living together or not, among second-generation immigrants and non-immigrants in any of the categories of immigrant groups.

\section{DISCUSSION}

This study was conducted to explore if and how second-generation immigrant children differ in their self-reported mental health at the age of 12 from non-immigrant children in Sweden. The main results of the study may be summarized in two main findings.

First, the analyses showed that second-generation immigrant children as a group did not differ from the non-immigrant children in their presentation of self-reported mental health, neither when gender, family structure and parental educational level were adjusted for. Further no significant association with children's mental health were found in the results from 
the first category group, i.e. the category groups based on both parents immigrant status, or the second category group, i.e. the category groups based on parents' country of origin. A previous report from the SESBiC-study indicated an increased risk of psychosocial problems in the pre-school years among second-generation immigrant children according to parentreports (19). Studies show that parent-reports and self-reports do not show high correlation (29). Since that study the families have lived in Sweden longer an have had a better possibility of adapting to the Swedish culture, school- and health care system and therefore the children in our study would be more likely to present emotional and behaviour problems similar to those of the non-immigrant children. Studies in mental health among children and adolescents in Sweden have shown that preadolescent children generally report good mental health and, in general, better mental health than reported by adolescents and adults (18). We can only speculate if this pattern will emerge in a future follow-up of this birth cohort, showing, perhaps, an increased risk of mental disorders, self-harm- and suicidal behaviour as has been shown in earlier studies of second-generation immigrant adults (30-33). An important factor to keep in mind in all epidemiological studies, and especially when evaluating scores of mental health among individuals with different immigrant backgrounds is that different kinds of expectations and cultural values might have an impact on the way they score (33). However, a questionnaire which makes comparisons possible is needed and the SDQ and the CBCL/YSR are the most frequently used questionnaires in different countries and by that to some degree has minimized this problem of not being sensitive enough to cultural differences. Further, all second-generation immigrants are relatively adapted to the Swedish society considering that they are born in Sweden, speak Swedish and belong to the Swedish school- and healthcare system. In a future study of the SESBiC-data we will compare parental-, teacher- and self reports on mental health of second-generation immigrants 
as well as non-immigrant children in Sweden in order to better understand the complexity that lies behind responses to these questions.

Second, our study confirms the results of other studies (34), that mental health of boys differs from that of girls; boys more frequently display conduct and hyperactivity problems as well as greater deficiencies in prosocial behaviour while girls more frequently display emotional problems. These results indicate that our study population followed the pattern for gender differences in mental health that has previously been observed in the general population of children in Sweden (34).

A strength of this study, in contrast to the majority of other studies in the field where the respective study groups cover a wide age span, was that all the children in the study were assessed at the same age. Since mental health varies considerably during the preadolescent and adolescent years (18) more age-specific studies are required.

There were some limitations associated with the study worth discussing. The study measures mental health among second-generation immigrant children in small cities in southern Sweden. Perhaps the results might have been different if bigger cities were included in the study where more subcultures based on ethnicity develop and consequently makes integration more difficult. The parent's refugee status was not known. That would have been of great interest to in our material evaluate the self-reported mental health in this subgroup since studies in the field has reported contradictory results (35). The drop out rate was higher among children whose mothers had a high stress score at the baseline study. This was expected and a high drop out is often seen in longitudinal studies with the aim to assess and interview participants on several occasions' (36) - this can of course have influenced our results. The drop out rate among children whose parents were both immigrants as well as among children whose parents came from a country outside of Europe was higher than the drop out rate for the other children. Since $86 \%$ of the parents in families where both parents 
were immigrants came from a country outside of Europe those two drop out analyses basically assessed the same children. A possible explanation of the higher drop out may be that because of language barriers the parents had more trouble understanding the content of the study and therefore chose not to fill out the consent form allowing the child to take part in the study. The drop out analysis showed, however, that there was no significant difference among the participant and non-participant children of two immigrant parents regarding maternal socio demographic stress or acculturation level in the family, which indicated that the drop out in this important group was not particularly selective. There was no significant difference between participants and non-participant at the 12-year follow up regarding earlier emotional and behaviour problems documented in the SESBiC-study at the age of 3 (19). That is valuable information, although it is also known that emotional and behaviour problems varies considerably in the childhood years (18).

The study size was sufficient for the analysis on mental health among secondgeneration immigrants as a group. Nevertheless, when stratified for parent's country of origin and parental immigrant status the groups became small and consequently these results should be interpreted carefully.

The mental health outcome of the children in this study was measured using dichotomized analysis of the SDQ. This could diminish the possibility to uncover true differences between second-generation immigrants and non-immigrants. When using the whole variation of the scales (t-test) some difference were found. For instance, secondgeneration immigrant girls reported less total problems than non-immigrant girls and children of two immigrant parents reported less emotional problems than children with non-immigrant parents. Both these differences supported the main findings that second-generation immigrant children at the age of twelve have a mental health comparable to non-immigrant children. 
In summary, no difference was found between second-generation immigrants and the general population, and that is a valuable contribution to the understanding of how preadolescents born in Sweden, but of different parental immigrant backgrounds, evaluate their own mental health. Future follow ups will have as one goal to determine if this positive development in second-generation immigrants is maintained through the adolescent years.

\section{ACKNOWLEDGEMENTS}

Thanks to the Swedish Council for Working Life and Social Research, the May Flower of Charity for financial support and to the statistician MA Marie Bladh for statistical advice.

Declaration of interest: The authors report no conflicts of interest. The authors alone are responsible for the content and writing of the paper. 


\section{REFERENCES}

(1) Statistics Sweden, Population statistics for 2009. Written communication 2010.

(2) Svensson M, Hagquist C. Adolescent alcohol and illicit drug use among first- and secondgeneration immigrants in Sweden. Scand J Public Health 2010;38:184-91.

(3) Stevens GW, Vollebergh WA. Mental health in migrant children. J Child Psychol Psychiatry 2008;49:276-94.

(4) Harker K. Immigrant generation, assimilation, and adolescent psychogical well-being. Social Forces 2001;79:969-1004.

(5) Rousseau C. Living conditions and emotional profiles of Cambodian, Central American, and Quebecois youth. Canadian Journal of Psychiatry 2000;45:905-11

(6) Alati R, Najman JM, Shuttlewood GJ, Williams GM, Bor W. Changes in mental health status amongst children of migrants to Australia: a longitudinal study. Sociol Health Illn 2003;25:866-88.

(7) Klimidis S, Stuart G, Minas IH, Ata AW. Immigrant status and gender effects on psychopathology and self-concept in adolescents: a test of the migration-morbidity hypothesis. Compr Psychiatry 1994;35:393-404.

(8) Sam DL, Virta E. Intergenerational value discrepancies in immigrant and host-national families and their impact on psychological adaptation. J Adolesc 2003;26:213-31.

(9) Vollebergh WA, ten Have M, Dekovic M, Oosterwegel A, Pels T, Veenstra R, et al. Mental health in immigrant children in the Netherlands. Soc Psychiatry Psychiatr Epidemiol 2005;40:489-96.

(10) Stevens GW, Pels T, Bengi-Arslan L, Verhulst FC, Vollebergh WA, Crijnen AA. Parent, teacher and self-reported problem behavior in The Netherlands: comparing Moroccan immigrant with Dutch and with Turkish immigrant children and adolescents. Soc Psychiatry Psychiatr Epidemiol 2003;38:576-85. 
(11) Janssen MM, Verhulst FC, Bengi-Arslan L, Erol N, Salter CJ, Crijnen AA. Comparison of self-reported emotional and behavioral problems in Turkish immigrant, Dutch and Turkish adolescents. Soc Psychiatry Psychiatr Epidemiol 2004;39:133-40.

(12) Darwish Murad S, Joung IM, van Lenthe FJ, Bengi-Arslan L, Crijnen AA. Predictors of self-reported problem behaviours in Turkish immigrant and Dutch adolescents in the Netherlands. J Child Psychol Psychiatry 2003;44:412-23.

(13) Vaage AB, Tingvold L, Hauff E, Ta TV, Wentzel-Larsen T, Clench-Aas J, et al. Better mental health in children of Vietnamese refugees compared with their Norwegian peers - a matter of cultural difference? Child Adolesc Psychiatry Ment Health 2009;3:34.

(14) Peña JB, Wyman PA, Brown CH, Matthieu MM, Olivares TE, Hartel D, et. Al. Immigration generation status and its association with suicide attempts, substance use, and depressive symptoms among latino adolescents in the USA. Prev Sci 2008;9:299-310.

(15) Hamilton HA, Noh S, Adlaf EM. Adolescent risk behaviours and psychological distress across immigrant generations. Can J Public Health 2009;100:221-5.

(16) Pumariega AJ, Rothe E, Pumariega JB. Mental health of immigrants and refugees. Community Ment Health J 2005;41:581-97

(17) Noirhomme-Renard F, Deccache A. [First-generation immigrant adolescents' physical and mental health and behaviors]. Arch Pediatr 2007;14:1020-7.

(18) Petersen S, Bergström E, Cederblad M, Ivarsson A, Köhler L, Rydell A, et al. Barn och ungdomars psykiska hälsa i Sverige. 2010; Available at: http://www.kva.se/Documents/Vetenskap_samhallet/Halsa/Utskottet/kunskapsoversikt1_halsa _sve_2010.pdf.

(19) Cederblad M, Höök B. [Psychosocial health among second-generation immigrant children in preschool age: risk- and resilient factors] Psykosocial hälsa hos andra 
generationens invandrarbarn under förskoleåren: risk- och friskfaktorer. Socialmedicinsk tidskrift 2006;83:217-29.

(20) Cederblad M, Berg R, Höök B. Regional studie av barns psykiska hälsa. 2002;36.

(21) Cederblad M, Höök B, Berg R. [Screening of psychosocial risk factors during infancy and childhood]. Socialmedicinsk tidskrift 2005;82:158-70.

(22) Höök B, Cederblad M, Berg R. Prenatal and postnatal maternal smoking as risk factors for preschool children's mental health. Acta Paediatr 2006;95:671-7.

(23) Goodman R. The Strengths and Difficulties Questionnaire: a research note. J Child Psychol Psychiatry 1997;38:581-6.

(24) Goodman R, Renfrew D, Mullick M. Predicting type of psychiatric disorder from Strengths and Difficulties Questionnaire (SDQ) scores in child mental health clinics in London and Dhaka. Eur Child Adolesc Psychiatry 2000;9:129-34.

(25) Vostanis P. Strengths and Difficulties Questionnaire: research and clinical applilcations. Curr Opin Psychiatry 2006;19:367-72.

(26) Malmberg M, Rydell AM, Smedje H. Validity of the Swedish version of the Strengths and Difficulties Questionnaire (SDQ-Swe). Nord J Psychiatry 2003;57:357-63.

(27) Svedin CG, Priebe G. The Strengths and Difficulties Questionnaire as a screening instrument in a community sample of high school seniors in Sweden. Nord J Psychiatry $2008 ; 62: 225-32$.

(28) Van Roy B, Grøholt B, Heyerdahl S, Clench-Aas J. Self-reported strengths and difficulties in a large Norwegian population 10-19 years : age and gender specific results of the extended SDQ-questionnaire. Eur Child Adolesc Psychiatry 2006;15:189-98.

(29) Montgomery E. Self- and parent assessment of mental health: Disagreement on externalizing and internalizing behaviour in young refugees from the Middle East. Clinical Child Psychology \& Psychiatry 2008;13:49-63. 
(30) Hjern A, Allebeck P. Suicide in first- and second-generation immigrants in Sweden: a comparative study. Soc Psychiatry Psychiatr Epidemiol 2002;37:423-9.

(31) Saraiva Leao T, Sundquist J, Johansson LM, Johansson SE, Sundquist K. Incidence of mental disorders in second-generation immigrants in sweden: a four-year cohort study. Ethn Health 2005;10:243-56.

(32) Jablonska B, Lindberg L, Lindblad F, Hjern A. Ethnicity, socio-economic status and selfharm in Swedish youth: a national cohort study. Psychol Med 2009;39:87-94.

(33) Hunt SM, Bhopal R. Self report in clinical and epidemiological studies with non-English speakers: the challenge of language and culture. J Epidemiol Community Health 2004;58:618-22.

(34) Lundh LG, Wangby-Lundh M, Bjarehed J. Self-reported emotional and behavioral problems in Swedish 14 to 15-year-old adolescents: a study with the self-report version of the Strengths and Difficulties Questionnaire. Scand J Psychol 2008;49:523-32.

(35) Vaage AB et al. Better mental health in children of Vietnamese refugees compared with their Norwegian peers--a matter of cultural difference? Child Adolesc Psychiatry Ment Health 2009;3:34.

(36) Mann CJ. Observational research methods. Research design II: cohort, cross sectional, and case-control studies. Emerg Med J 2003;20:54-60. 
Table 1. Odds ratios in predicting each Strength and Difficulties Questionnaire subscale using immigrant status, gender and socio demographic background variables. Each subscale is modelled separately.

\begin{tabular}{|c|c|c|c|c|}
\hline \multirow[b]{3}{*}{ Emotional svmpto } & \multirow[t]{2}{*}{ Odds Ratio } & \multicolumn{2}{|c|}{ 95.0\% CI for Odds Ratio } & \multirow[t]{2}{*}{ p-value } \\
\hline & & Lower & Upper & \\
\hline & & & & \\
\hline Immigrant status & 0.553 & 0.195 & 1.564 & 0.264 \\
\hline Gender & 0.358 & 0.205 & 0.623 & 0.000 \\
\hline Family structure & 1.150 & 0.659 & 2.008 & 0.622 \\
\hline Parental education & 1.181 & 0.711 & 1.961 & 0.520 \\
\hline \multicolumn{5}{|c|}{ Conduct problems $\geq 90^{\text {th }}$ percentile } \\
\hline Immigrant status & 0.858 & 0.412 & 1.788 & 0.682 \\
\hline Gender & 2.783 & 1.715 & 4.517 & 0.000 \\
\hline Family structure & 1.543 & 0.945 & 2.519 & 0.083 \\
\hline Parental education & 1.103 & 0.699 & 1.739 & 0.675 \\
\hline \multicolumn{5}{|c|}{ Hyperactivity $\geq 90^{\text {th }}$ percentile } \\
\hline Immigrant status & 0.823 & 0.360 & 1.881 & 0.645 \\
\hline Gender & 2.589 & 1.507 & 4.448 & 0.001 \\
\hline Family structure & 0.836 & 0.451 & 1.551 & 0.570 \\
\hline Parental education & 2.018 & 1.167 & 3.490 & 0.012 \\
\hline \multicolumn{5}{|c|}{ Peer problems $\geq 90^{\text {th }}$ percentile } \\
\hline Immigrant status & 0.202 & 0.027 & 1.492 & 0.117 \\
\hline Gender & 1.403 & 0.736 & 2.671 & 0.303 \\
\hline Family structure & 2.424 & 1.267 & 4.641 & 0.008 \\
\hline Parental education & 0.949 & 0.498 & 1.808 & 0.873 \\
\hline \multicolumn{5}{|c|}{ Total difficulty score $\geq 90^{\text {th }}$ percentile } \\
\hline Immigrant status & 0.684 & 0.287 & 1.633 & 0.393 \\
\hline Gender & 1.551 & 0.950 & 2.534 & 0.079 \\
\hline Family structure & 1.214 & 0.705 & 2.089 & 0.484 \\
\hline Parental education & 1.666 & 0.999 & 2.780 & 0.050 \\
\hline \multicolumn{5}{|c|}{ Prosocial behaviour $\leq 10^{\text {th }}$ percentile } \\
\hline Immigrant status & 0.726 & 0.302 & 1.747 & 0.475 \\
\hline Gender & 3.283 & 1.848 & 5.830 & 0.000 \\
\hline Family structure & 1.171 & 0.653 & 2.101 & 0.596 \\
\hline Parental education & 1.085 & 0.645 & 1.823 & 0.759 \\
\hline
\end{tabular}

Logistic regression. Dependent variables: SDQ (emotional symptoms, conduct problems, hyperactivity, peer problems, total score and low prosocial behaviour). Independent variables (0 is used as a reference level): immigrant status (both parents Swedish born 0/at least one parent immigrant 1), gender (girl 0/boy 1), family structure (living with both biological parents 0/not living with both biological parents 1 ), parental education (university or college $0 /$ compulsory school or high school 1). 